As the Journal is the great bond of union among the members of the Association, we have always reported Association Intelligence at a considerable length, and have likewise given up a good deal of space to the letters of members; but we wav eyet to discover that this has been either an unprofitable or an unacceptalle course of proceeding. We have expressed our own views freely; and therefore, unless we had also given latitude to others to do the same, the Journal would have been perverted from its legitimate use, as the organ of the whole of our body. Regarding gratuitous advice, compulsory vaccination, Sabbath observance, chloroform in midwifery, etc., ctc., wc have, as in duty bound, stated our own views, as those questions arose before the medical world; but we have also given fair scope to those collearues who differed from us in opinion. It ought to be obvious to those who grumble at the amount of space which is occasionally occupied by letters, that the Journal is equally the property of all the members of the Association, and that we are bound, as far as possible, to enable those who have something to communicate to their colleagues, to communicate it through the medium of their own Journal.

The daily correspondence which we have with our fellow associates in all parts of the kingdom convinces us that the plan which we published in our first number, under the sanction of the Journal Committee, has given general satisfaction both in its promise and in its performance. We therefore feel no inclination to alter the character of our programme, though we shall stcadily strive for ampler resources wherewith to enhance the efficiency of the performance. We regard the introduction of Medical Meteorology into our weekly table of contents as a great step in this direction. This important addition to our original programme has anxiously engaged our attention for many months past, and it has also involved the writing and the reading of some hundreds of letters during that period. We felt that, until the details of our plan were fully matured, we ought not to broach our project, as we knew that the public discussion of the difficulties which we had to encounter was more likely to impede than to facilitate the progress of our arrangements.

An honourable and a lasting renown will belong to the Provincial Medical and Surgicul Association, if it be able to maintain the lead which it is about to take in collecting and arranging the facts of a department of science which, though yet in its infancy, has commenced to shed the rays of morning upon fields of pathology which have hitherto been wrapped in clouds of impenetrable darkness. Let the Association be ever animated in this and all its enterprizes by the conviction that, if it make a right use of its great resources, it can do more than any College or Corporation has yet done or can do to give to the medical profession its legitimate and salutary influence in the cconomics of the state. The Association cannot but be ennobled in the cyes of the world by maintaining a healthful purity of ethics within its pale, and by applying its organization to the elucidation of grand problems in hygienics and pathology which do not admit of being tarnished with even the suspicion of selfishness.

\section{ORIGHIAL COMDTUITCATIONS.}

\section{ON THE TOPICAL TREATMENT OF HOOPING-COUGH.}

By EBEN WATSON, A.M., M.D., Professor of the Institutes of Medicine in the Andersonian University, Glasgow.

IT is now nearly six ycars since I began to use topical applications to the pharyngo-laryngeal membrane, in cases of hooping-cough, in the hope of mitigating the paroxysmal spasms of the glottis which form so important a feature of that disease; and, being well satisfied with the results of the treatment, I published an account of it in the Edinburgh Monthly Journal of Medical Science for 1849, p. 1287. Seeing, moreover, that no therapeutic measure can be successful, or ought to be adopted, unless it is founded upon a true pathology of the disease for which it is proposed as a remedy, I endeavoured to point out, in the paper referred to, the thcory of hooping-cough which commended itself to my mind, and which seemed to me at once to establish the reasonableness of the topical plan of treatment, and to explain the want of success which had attended the employment of general means in cases of that disease.

All experience bears me out in stating that the first and second stages of hooping-cough arc marked by catarrhal inflammation of the larynx, trachea, and bronchi. In severe cases, this inflammation involves the whole thickness of the mucous membrane, and may even spread to the minute air-tubes, or to the pulmonary cells, before the spasmodic stage has well commenced. More or less speedily, however, the pharyngeal and bronchial branches of the vagi nerves become involved in the morbid action. It is a common opinion, that this nerve becomes inflamed; but we are not warranted by the results of post mortem inspections, nor by any data of "living pathology", in assuming that opinion as proved. At all events, a small amount of inflammatory action, such as may be called irritation, is sufficient to account for the symptoms of the second stage, in which the hoops occur. This feature in the pathology of hooping cough is interestingly proved by Romberg (Diseases of the Nervous System, Sydenham Society's edition, vol. i, p. 349), by experiments on the lower animals, performed by himself and others. But probably the cases which happened to Sir Astley Cooper and to M. Gendrin, both shortly stated by Romberg in the passage referred to, may be still more convincing to most minds. They were cases of inflammation, the one of the parotid gland, and the other of an aneurismal sac, in the vicinity of the pneumogastric trunk, and occasioning paroxysms of cough and dyspnœa. To these we might add the cases of small bodies, such as fish bones, etc., sticking about the pharynx, and causing similar symptoms; many of which are now on record.

It would seem, then, to be satisfactorily proved that the morbific agent in cases of hooping-cough commences its operation by producing inflammation of the pharyngeal and bronchial mucous membrane; and secondarily, irritation of the pneumogastric nerves. Now, it is obvious that such cases only differ from ordinary bronchitis, so far as their mechanism is concerned, in the amount of irritation produced in the pneumogastric nerves. In ordinary bronchitis, this is nothing more than what will suffice to produce those expulsory efforts in which coughing consists; while in hooping-cough it is so great as to excite again and again a spasmodic closure of the glottis, which at once prevents the expulsion of the offending mucus, and so impedes inspiration as to occasion the well known crowing sound that accompanies the act. In this stage, the stomach likewise becomes affected, and vomiting is a common termination of a fit of coughing; but this is easily explicable on the acknowledged truths of physiology-the irritation of any one set of branches, or of the trunk of a nerve, being capable of producing action in organs supplied by other nerres 
having a common centre, and, $a$ fortiori, by other branches of the same nerve-trunk.

Two questions are yet necessary to be considered, in order to complete a theory of hooping-cough. These are: first, In what relation does it stand to its so called complications ? and second, What is the nature of the agency which starts the train of morbid effects of which we have been treating?

There would be little need of remark on the first of these points, were it not that almost all its attendant symptoms have been considered as part of the disease, and not as complications at all. It is indeed difficult to draw the line of demarcation between the bronchial inflammation which is essential, and that which is accidental to the hoopingcough; but, as we have certain well marked cases of the latter, in which the former state is either absent, or confined to the pharyngo-laryngeal membrane, I think it fair to consider all inflammatory action beyond that as complicating the primary disease. The same, in my opinion, is true of inflammation of the air-cells, and still more so of those complications which cannot be considered as extensions of the primary effect of the morbific agent. I refer to cerebral and abdominal complications, to dilated bronchi or ruptured vessels, all which may be traced, more or less directly, to the violence of the paroxysms of dyspnœa.

On the second point, I have only to remark, that the almost invariable occurrence of hooping cough, once in the life of every person exposed to its influence, its exhausting his susceptibility to suffer from it in the first attack, and its undoubted communicability from one patient to another, in the same manner as other diseases which are usually considered infectious or contagious, warrant the common belief that the disease is due to the opcration of a morbid poison in the blood, the effects of which are manifested in the manner formerly explained. This poison seems to circulate in the system for a time before producing decided symptoms of the discase. About eight days usually elapse, during which the patient is affected with fever and other symptoms of common catarrh, hefore the stage of hooping commences at all. But as soon as the spasmodic stage is fairly established, all the symptoms of general disorder in most cases subside; and, unless some complication occur, the disease remains, during its future course, a local affection of the larynx and bronchi, without any evidence of a morbid condition of the circulating fluid. I think it more than likely, then, that the poison of hooping-cough is generally eliminated or rendered innocuous by the time that the spasmodic stage of the disease has reached its acme.

The objection, then, which I have heard urged against the topical treatment of hooping-cough, viz., that it does not aim at neutralising the morbid poison which originated the disease, but only at removing or mitigating the local effects thereby produced, must lose its point, if the facts just alluded to be admitted; and I believe few will doult them, who have had much experience of the disease; for these facts prove that the hooping-cough is, for a long period of its course, the evidence rather that a peculiar mor bid poison has been than that it is then present in the blood; and if it be remembered that it is in this very period that complications are most apt to arise and to endanger the life of the patient, the importance of checking the progress and counteracting the results of the morbid poison will not be donied, even though the measure by which this is to be accomplished lays no claim to the doubtful title of a hæmatic or blood medicine. For it ought not to be forgottcn, that we have no very satisfactory proof that any of the remedies in use for other zymotic diseases act as direct antidotes to the morbid poisons which originated them. The action of quinine in cases of intermittent fever is by no means so uniform or certain as we should expect in an anti. dote to the paludal poison; while at least one other substance of a totally different nature, viz. arsenic, has produced results almost, if not quite as farourable. And besides, many other therapeutic agents, evidently acting upon the local and secondary effects of the poison, such as bleeding, mercury, etc., nearly approach, in their curative influence upon the disease, those which are usually considered the more direct and antidotal remedies. The prevention of small-pox by vaccination is hardly a case in point; because it is merely an instance of one morbid poison exhausting from the blood the substance on which the other poison acts. It must therefore be confessed that we at present know little either of the nature or modus operandi of the morbid poisons, and perhaps even less of the antidotes that may be capable of counteracting them in the blood. While, then, we eagerly seek for the elements of induction regarding zymotic diseases; nay, while we admire the beauty of Liebig's fermentation theory of their origin, so ably supported by Dr. Carpenter in a recent number of the Medico-Chirurgical Review (No. xxi, p. 159), still it is useless to dream of founding, as yet, any rational system of therapeutics on such imperfect though beautiful hypotheses.

If, then, we cannot at present hope to be able to treat zymotic diseases by remedies aimed at neutralising the morbid poisons which remotely excite them, the only reasonable plan of dealing with them is to shorten or cure the secondary effects of these primary agents. To take the case of hooping-cough; we do not yet know of any medicinal substance that deserves to be called an antidote to the poison which at first excites the disease. We have, however, learned by observation that it produces two secondary diseases; viz., inflammation of the mucous membrane of the air-passages, and next, irritation of the vagi nerves. While then we have no means of treating, with any hope of success, the remote cause of these morbid states, we can, with almost certain success, treat the latter; and having cured them, it is matter of experience that the poison becomes speedily eliminated, and does not reproduce itself. I consider this a sufficient defence of the topical treatment against the objections of those who would have us, in fact, cease to treat zymotic diseases until we discover antidotes to their remote causes.

Let us now consider shortly in what way the solution of caustic, applicd to the interior of the pharynx and larynx, acts in curing the local effects of the poison of hoopingcough. M. Joubert scems to think that the topical remedy only affects the inflammatory state of the mucous membrane, and the excessive secretion of mucus which results therefrom, and to which he attributes the spasmodic element of the disease. I have not been able to see his memoir, which is published in the Recueil des Travaux de la Société Médicale de l'Indre et Loire, ler et 2de trimestre de 1851 : but the following passage sufficiently indicates his opinion. “M. Joubert n'a pas, du reste, été conduit i employer ce traitement dans la coqueluche par le désir de modifier l'élément spasmodique en agissant sur les nerfs qui se distribuent aux voies respiratoires, mais seulement par l'idée théorique de modifier la disposition en vertu de laquelle s'opère la sécrétion morbide, a la présence de laquelle il attribue la toux convulsire." (Bulletin Génércel de Thérapeutique, tome xlii, p. 4l.) Now, as the only disposition in the mucous membrane which determines the secretion is its inflammatory excitement, so it is unon that alone that $M$. Joubert considers the topical remedy to act. Nor do I seek to dispute the fact that such an action is effected, nay, that it is first effected in every case of hooping-cough in which the topical treatment is employed. But if the case be well watched, it will be found that, after the inflammation of the pharyngo-laryngeal mucous membrane is subdued, and after the expectoration has diminished in amount and in bulk, the hoops continue, though, in general, they are less frequent and less severe. In most cases, the remedy must yet be continued for a short time before the cure can be accounted complete. When, however, the inflammation of the larynx or trachea happens in any case to be peculiarly severe, the cure by topical means is always postponed for a longer time than usual; and this would seem to show that the nervous or spasmodic element seldom gives way before the inflammatory.

Not long ago, I treated two children in the same family, who were attacked at the same time by the hooping-cough. The one was a baby at the breast, and was very severely 
affected, insomuch that his life was for a time in danger. I began the topical treatment about the middle of the spasmodic stage; and in eight days he had ceased to hoop, and in a short time to cough at all. Ilis sister, the other patient, was about two years and a half old, and apparently much less severely affected with the hooping-cough; but she had just recovered from an at task of croup when she was seized with that disease, and at first her cough had much of the croupy sound. I treated her puri pessse with her brother; and yet her disease continuel two weeks longer than his.

On the other hatud, I have known of cases irregularly treated by the tol,ieal method, in which the inflammatory element was sublued, anl in which the hooping continued, though in a mili deyrec, for a considerable time longer. But the most convincing proof that the solution of caustic has a decided and sedative influence on the spasmodic elcment of hoopine-cough, or, in other words, on the excited state of the extreme lira!ıches of the vagi nerves in the throat and laryrix, is the fact, which my experience demonstrates, that the topical plan is most specdily effectual in the last stage of the lisease, when all the previous symptoms of inflamination have disi!lueared, and the hoop alone remains. I have scen a number of such enses, in which the children secmed worn oit by the disease, and in which general remedies hat heen lone lout vainly enployed. In all these cases, the very first touch has a markedly beneficial effect; and its repetition for a comparatively few times suffices to perfect in cure.

When, however, we rememler how much the nerves of any part are implicated in its intlammation, it may be, after all, that the affection of the pharyngeal and bronchial nerves, which oceasions the spasmorlic parexysms of hooping cough, $i$ : of the same nature; and that we are warranted in ingreeing in the main with M. Joulert, that the topical application of solution of caustic: opcrates solely in subduing inflammation. Since, then, that morbid state exists in the bronchial mucous memlinalic as constantly in cases of spasmodic asthma * as in those of hooping cough, the rationale of the topical remedy lecomes ruluceil to the counter action of only one morlid state; and we may call it an antiphlogistic sedative of the pharyngo-laryngeal mucous membrane. But this, in my opinion, can only be said with truth of the less sthenic decrrees of intlammation, as I have explained in another paper (Dublin (ewarterly Journal of Med licine', August 18.5):2). The practical rule, however, remains importanty true, that the remedy should be continuced so long as the slightest hoop is heard, although all the ordinury sympioms of inflammatory action, such as bronchitic riles or bulky expectoration, have been subdued for some time. If this rule is not strictly attended to, a relapse will ere lons le the consequence; and the treatment will have to be continued nearly as long as if it had never been conmenced at all. liut if the disease be thus thoroughly subdued in its first attack, no recurrence of it need be apprehended during the patient's life. I make this statement in full knowledge of the sncecerling history of all the cases in which I have cmployed the topical treatment; and many of them have hecon ingain freely exposed to infection.

Regarding the inode of prosecuting this topical treatment, I may now he allowed to make a few remarks, suggestel by the statements or objections of other physicians, which I have cither rcarl or hearl expressed in conversation.

1. The most convenient instrument for applying any solution to the throat or larynx, is the sponge and whalebone. The forceps suggested hy Dr. Cotton, and which has one liml. covered with sponire, is needlessly complicated, and much more ajt to injure the delicate glottis. Nor is it fitted to olviate the supposed danger of the detachment of the sponge in the windpipe of the patient, which gave risc to the idlea of Dr. Cotton's instrument at the first. It is, inrleed, quite a mistake to think that there is any strain upou the sponge, when once it is within the

* I have recummeniled the topical treatment of the larynx in rases of spasmodie asthima, in another paper. Sce Glasgonr. Medical Jourmal, No. 1, p. xis, p. 46:2. larynx. That organ cannot contract so as to dotain the sponge; and it must have been very carelesely fixed on the whalebone, if the glottis could detach it during its withdrawal. Indeed, a skilful operator will seldom feel the contraction of the glottis at all; for, as the pationt inspires immediately on the introduction of the sponge into the larynx, the muscular ralve becomes relaxed and permits its easy withdrawal. The strong contraction which I have myself often felt, and which I have known many to mistake for that of the glottis, is in reality a proof that the sponge is not in the windpipe at all, but is caught by the pharynx immediately behind it. And this gives colour to the amusing story of the musician, whose larynx was being touched by a learned physician, who, on withdrawing the whalebone, found it lestitute of the sponge. The physician was in great alarm; but the patient neither choked nor died. Ere long, however, he vomited the sponge from his stomach. It had been caught by the pharynx, and swallowed.

If the instrument is at all well made, this could never happen, except from one circumstance, which ought to be known by every person who atteupts the topical treatment of the larynx, especially among chililen. It is, that the culstic solution in a short time destroys the thread with which the sponge is fastened to the whalebone. The simple and ecrtain way, then, of aroiding any such accident as that to which I have been referring, is to have the sponge frequently renewed.

2 . It would appear, from the following passage, that $\mathbf{M}$. Joubert supposes me to have recommended the indiscriminate employment of a solution of the nitrate of silver of uniform strength: "Il n'y a pas une grande différence entre le procédé opératoire suivi par MI. Joubert et celui de M. Witson; seulement le premier emploie des solutions concentrées à des degrés différents, depuis 1 gramme jusqu'à + grammes de nitrate d'argent pour 30 grammes d'eau distillée, et qu'il désigne par les numéros 1, 2, 3, 4." (bulletin de Therapeutique, tom. xlii, p. 41.) Now, saving the designation of the solutions by the numerals $1,2,3$, and 4 , which is loubtless a convenient plan when employing them on a large scale, there is no novelty in this practice of M. Joubert. For in my original paper on the hooping cough (Elinburgh Monthly .Oounal, Dec. 1849), I distinctly state that "the ordinary strength of the solution which I have used in the treatment of hooping cough, is $\mathrm{gr}$. $\mathrm{xv}$ of the nitrate of silver to the ounce of distilled water; but, in some cases, I have with advantage increased it to $\ni i j$ of the salt in the ounce of water." From an enlarged experience of the treatment in question, I can now be still more precise; for I have found that in the carly stage of the disease, and just in proportion to the intensity of the inflammatory process which may be present, so ought the solution employed to be proportionally week. Afterwards, when the nervous symptoms predominate, the solution may with advantage be strengthened; but it is impossible to lay down rules that will universally apply to different cases, or even to the same case on different days. This must be left to the judgment of the practitioner; and he will find it quite necessary, for the favourable progress of the case, that he should use his discretion in regard to it, as much as to the administration of emetics or laxatives.

3. Dr. Scott Alison has lately drawn the attention of the profession to the application of several other substances to the larynx; and perhaps some of them, such as solution of morphia, may be occasionally used with advantage in cases of hooping-cough. I merely make this as a suggestion; but I have, from some little experience of its effects, a better founded opinion of another substance, which has not. hitherto, I belicve, been used as a topical application to the larynx. I refer to the hyposulphite of soda and silver, to which my atteution was first directed by a notice in the Nedico-Chirurgical Review (No. XXII, p. 567). This salt has a very soothing effect on the larynx when its lining membrane is irritated by a vitiated, and, as is generally the case, an acid secretion; and I entertain the hope that its solution will form a useful topical application in the first stages of hooping-cough. I intend, however, in due time to lay before the profession a fuller account of a trial, 
which I am at present making, of the value of this alt in laryngeal cases.

4. In some cases of hooping-cough, an obstacle is presented to the topical treatment, by a state of matters which is, in other respects, by no means unfarourable to the patient. I mean the irritability of his stomach, which makes the slightest touch of the sponge in the throat the signal for violent retching and vomiting, if the stomach be full. I very often, therefore, find it necessary to prescribe for this symptom frequent small doses of heary magnesia, combined sometimes with a few grains of the trisnitrate of bismuth. Such simple treatment seldom fails to mitigate the vomiting sufficiently to admit of the continuance of the topical applications.

5. These applications should be renewed at least every second day; but, if their commencement has been delayed till the disease is at its height, or if the hoops are very violent from the first, they should be repeated more frequently: and, for the reason stated above, the time of making them should be selected so as to have the stomach empty ; and the patient should not be allowed to eat for an hour or two afterwards, else the feeling of rawness in the throat, which follows each application of the remedy, will be unnecessarily increased, and occasionally hooping and vomiting will be induced.

j. In making these applications of solution of caustic to the throats of children, everything in the shape of a formidable spatula should be dispensed with, and either a common teaspoon, or the index-finger of the left hand, should be used. In all cases in which it is important to pass the sponge into the larynx, I consider it quite necessary to introduce the finger into the patient's mouth, and to touch with it the tip of the epiglottis, along the surface of which the instrument may be glided down with certainty to the rima glottidis. And if this proceeding be performed at once with firmness, few children either can or will resist it hy struggling, or by biting the operator's finger; but much patience and tact is sometimes necessary to school them to submission in the beginning of the treatment. After a few times, no more trouble is experienced.

Pursued in this way, with these precautions, and with a prudent attention to the diet and regimen of the patients, the topical treatment of hooping-cough wonderfully shortens the disease, and renders it nearly as mild as ordinary catarrh. Complications seldom occur, and thus the disease is stripped of its most formidable characteristic. Hence it is that I can give the following favourable numerical account of the results of the treatment in question.

$$
\begin{aligned}
& \text { a fortuight. } 3-4 \text { whs. trentmeent. }
\end{aligned}
$$

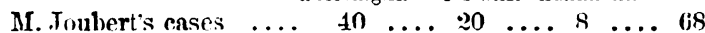

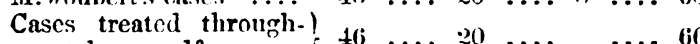

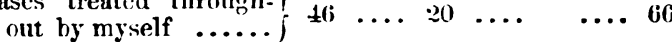

$$
\begin{aligned}
& \overline{86} \quad \overline{40} \quad \overline{8} \quad \overline{134}
\end{aligned}
$$

In contrast with this table, I subjoin another of the ordinary duration of the disease when treated in the usual manner, as stated by a few of our best and most recent authorities.

Dr. P. Williams* states it at from 2 to 4 months, or more than a year.

Dr. Copland+ states it at from 32 days to 5 months, or more.

Dr. C.J. H. Williams states it at from 6 to 10 weeks, or more.

J)r. Walshe§ states it at from $\varangle$ to 1:3 weeks, or more.

Dr. West states it at from 8 to 14 wetks, or more.

NM. Barthez et lilliet 9 state it at from 1 to 3 months, or more.

Averige of all the statements from......1 to $3 \frac{1}{2}$ months.

- Williams on Morbid Poisons, vol. i, p. 811

+ Dictionary of Medicine, pr. $36 \mathrm{6}, 23 \%$

I ibrary of Nedicine, vol. pii, $p$,

Walshe on Disesses of the Chest, 418,419

4 Lectures on Diseuses of Children, p. 279.

7 Traité Pratique et Clinique des Maladies des Enfants, 2me edition,

tom. ii, p. 624 .
I think it right to add to the abore computations, the following statement of Dr. Bobert Watt, whose treatise on the chin-cough, though published in 1813, may atill to consulted with advantage, especially in regard of the history of the disease. "Nothing," he writes, "can be move uncertain than the course and event of this disease. In the mildest form in which it appears, it usually continues for two, three, or four months ; in the more severe, it may last twice, or even thrice as long." (Treatire on the Nature, History, and Treatment of Chin-Cough. Glasgow, 1813, page 69.)

I have no ready means of shewing the proportion of deaths to attacks in this disease; but no one can dispute that it is a very considerable cause of the enormous mortality occurring among young children in this country. According to the reports of the Registrar-General, the deaths from hooping-cough in London stand in the proportion of 8.9 per cent. among females, and 6.2 per cent. among males, to the deaths from all causes under ten years of age. And in Glasgow, the proportion is nearly the same; the deaths from hoopingcough being 8.7 per cent. of the deaths from all causes under ten years of age.

Surely, then, a treatment which promised to diminish, or, perhaps, to annihilate, this very great mortality, ought to have been received with consideration by the profession. Such, however, has not been the case in the present instance: for, though such a promise has not only been giren by it, but rendered almost certain by the results of an extensive trial, yet such a reception has not been accorded to the topical plan of treating the hooping-cough; at least if I may judgre from the circumstance that few or none of our recent writers on children's complaints have noticed, far less recommended, the plan. Thus Dr. West, though he confesses that there is nothing "unreasonable in the expectation that a remedy (for hooping-cough) may some day or other be discovered which shall cut short its course with as much certainty as quinine arrests an intermittent fever, or which shall render the constitution insusceptible of its poison as infallibly as chicken-pox (cow-pox?) preserves from variola;" yet he adds, "at present no such remedy has been discovered; and though the severity of an attack of hooping-cough, or its duration, varies greatly in different individuals, during different epidemics, and at different seasons of the year, yet we are unable, by any medicinal agents, to produce effects such as in these cases flow from causes quite beyond our control."* But surely the numerical results just given prove in a manner beyond all cavil, that the simple treatment which $I$ have suggested is capable of cutting short the hooping-congh with as much ccrtainty as quinine arrests an intermittent fever; and moreover, that it renders the disease, while it lasts, both milder in type and safer to the patient than the most fa vourable circumstances of season or epidemic could possibly do. For it should be borne in mind, that the results alluded to have been obtained at different seasons of the year, in different countries, during different epidemics, and by different observers. Seldom, indeed, has any new remedy so well stood the test of such a varied and extensive trial. At the same time, I hope that the theoretical considerations which I have stated so fully, and which are the general expressions of so many individual facts, sifted and weighed according to the strictest method of induction, remore the topical treatment of hooping-cough from among the vague class of specifics, and place it among the agents of rational medicine.

In contrast with the disregard, which is indicated by the silence of English physicians, as to the topical treatment of hooping-cough, I could quote the favourable opinions of many continental writers. For example, not only has $M$. Joubert put the treatment to the test of an extensive trial, but Dr. Debout, in giving an account of it, alludes to his own experience in the following terms:- "Nous avons ou depuis, nous-même, l'occasion de vérifier les effets favorables de cette pratique dans plusieurs cas de cette maladie."

- West on Jiseases of Children, p. 208. Second edition : 1969. 
(Bulletin de Therapeutique, tome xnI, p. 41.) And in the recent edition of the elaborate treatise of $M$ M. Barthez et Rilliet, the topical treatment of hooping-cough obtains a place amongst the available remedies for the disease. I shall be excused for quoting their brief but sufficient description of the method:- "Le Docteur Watson a conseillé l'emploi de la cautérisation pharyngo-laryngée arec une solution de nitrate d'argent de 75 centigrammes aे 2 grammes 40 centigrammes pour $30 \mathrm{gr}$. d'eau distillée. M. Watson se sert d'une éponge solidement fixée à une baleine accourbée; la tête du malade étant fixée par une aide, et la langue prealablement abaissée, il porte l'éponge jusqu'à l'ouverture de la glotte; il résulte de cette petite opération une sensation de suffocation très légère et temporaire que l'enfant a bientot oublié." (Traité Clinique et Pratique des Maladies des Einfants, 2me edition, tom. II, p. 657, published in 1853.)

I hope, then, that it may not be utopian to expect that the day is not distant when the treatment, so well described by these excellent writers, and the usefulness of which I have now been enabled to establish, very mainly, through the generous zeal and untiring perseverance of another French physician, will be more favourably received in this country, and more generally adopted by British practitioners of medicine. Were such to be the case, I do not doubt that the result would be displayed in a marked diminution of mortality among children, and in the removal of a longstanding opprobrium to the healing art.

Glasgor, August 18:3.

\section{ON CHOLERA, AND ITS TREATMENT BY} COLD WATER AFFUSION OR DOUCHE.

By E. M. MAClIIERSON, Esq., late Surgeon in the Army.

Having had various opportunities of treating cholera, during a service of nine years in India, and of testing the efficacy of cold water affusion in many cases of the worst description, since June 1845, I belicve that a report upon this mode of treatment, which has been found so immediate in its effects, and beneficial in its results, will merit attention. And, if conclusions may be drawn from the ostensible principle of its action, the real nature of cholera cannot fail to be more distinctly recognised than has yet been acknowledged.

Beforc entering upon this report, it may be advisable, for the elucidation of the subject, to glance at the difference supposed to exist between cholera in Europe and cholera in Asia; and, for the better appreciation of the treatment proposed, to determine, from the copious and accurate data rccorded of cholera, what is the leading characteristic of the disease, and what ought to be the object of our treatment in regard to it.

That the difference supposed to exist between the Asiatic and European forms of cholera is one of degrec only, not of kind, will be evident on a cursory inquiry. IIence it will also be evident that the treatment applicable in the one form, is equally so in the other. In Asia, where the disease may be said to be indigenous, cholera, true to its history, bursts forth in all its vigour, and from the first appears in its advanced stage, or stage of collanse-in this country denominated its second stage. But when, after its onset in this advanced stage, it subsides in the virulence of its attacks, and the cases become milder, more amenable to treatment, and less rapidly fatal, it will be found to assume that form of the disease in which vomiting, purging, and cramps, prevail, and to be in every respect identical with the so-called European cholera.

In Europe, on the other hand, where the disease is almost invariably ushered in by vomiting, purging, and cramps, these symptoms constitute its first stage; but when these symptoms have ceased, and when, as dissolution approaches, the first has passed into the second stage, or stage of collapse, cholera in Europe will be found identical with cholera in Asia, whcre so many are struck down almost lifeless from the first.
How far these symptoms, vis. the romiting, purging, and cramps (upon which so much stress has been laid in the pathology and treatment of the disease), ought to be taken into account, the known history of cholers in all places, and under all circumstances in which it has shown itself, will satisfactorily decide.

If the value of a symptom, with a view to treatment, is. to be regarded in proportion to its influence on the fatality of a disease, then neither the vomiting, nor purging, nar cramps, will be found worthy of any consideration whatever in the treatment of cholera.

In the words of Dr. Copland, in his treatise on cholera: "The vomiting and purging, which are far from being the most dangerous symptoms, and are often the most remarkable in the least urgent cases, are generally slight, or at least not profuse, in those attacks where the sinking of the vital energies is the most rapid and greatest, and are readily allayed by medicines. The spasms are often slight, or nearly absent, in some of the most rapidly fatal cases."

That these remarks are fully borne out by the history of the disease, all who enter into the subject, and extend their observations beyond their own doors, may satisfy themselves. They may also infer, what must be obvious to most who have had experience of cholera in India, that the symptoms in question, - the vomiting, purging, and cramps,-if at all constant in their relation to the disease, seem to be so in an inverse ratio, as in compression of the brain, to the depression of vital energy. In other words, the collapse or asphyxia, which, with its sequelx, oppressed respiration, impeded circulation, coldness, blueness, etc., is the only invariable symptom, and therefore the leading characteristic of cholera, and ought to be the object of our treatment; not only because it is the only constant symptom, but also, perhaps rather, on the proof which experience will give all who have treated cholera, that reaction is the forerunner of every amelioration in the symptoms during an attack, and the only sign to be depended upon in forming a prognosis. It was in producing this reaction that the cold water effusion or douche was found so beneficial.

At Cawnpore, in June 1845, cholera broke out in the 53rd regiment, to which $I$ then belonged, with the same virulence as attended it in various localities throughout India during that and the succeeding year. Two men, the last survivors of several who had been attacked within two days, were sinking under that fatal collapse which alone, without any other symptoms, marked all the cases that had occurred in the regiment.

Every remedy that could be devised to produce reaction had been tried in vain; they might as well have been put into the patients' breeches pockets, or applied to the bedpost. The exhibition of the nitrous oxide gas was not only fruitless, but far from encouraging. The breathing under its use became more oppressed and hurricd; there was no pulse, nor was it rendered perceptible by the gas; and, as its continued exhibition distressed the patient, it was thrown aside as worse than uscless. In despair at the utter want of the most trivial effect from the remedies employed, I made trial of the cold water affusion. I desired the water-carrier to pour water from his leathern bag over one of the patients; and, as the effect was good, then over the other patient, placed naked on a bedstead in the verandah. Attendants were at the same time employed in rubbing the limbs and trunk with their palms, and afterwards with dry towels. A refreshing sensation and comparative reanimation having followed each repetition of this operation, it was had recourse to at intervals, though only with the success of having prolonged life, which was ebbing fast for some hours.

This success, poor though it was, seemed to warrant the conclusion that, had the remedy been applied while somewhat more of life remained, recovery might have been the result. To test this conclusion by experiment, an opportunity was not long wanting.

On the same evening, as if by some fatal blast sweeping over the barracks, several men were suddenly struck down in a state of collapse. Some retained consciousness (cholera 